\title{
Psychotic-like experiences in the general population: characterizing a high-risk group for psychosis
}

\author{
I. Kelleher ${ }^{1 *}$ and M. Cannon ${ }^{1,2}$ \\ ${ }^{1}$ Department of Psychiatry, Royal College of Surgeons in Ireland, Dublin, Ireland \\ ${ }^{2}$ Department of Psychiatry, Beaumont Hospital, Dublin, Ireland
}

\begin{abstract}
Recent research shows that psychotic symptoms, or psychotic-like experiences (PLEs), are reported not only by psychosis patients but also by healthy members of the general population. Healthy individuals who report these symptoms are considered to represent a non-clinical psychosis phenotype, and have been demonstrated to be at increased risk of schizophrenia-spectrum disorder. Converging research now shows that this non-clinical psychosis phenotype is familial, heritable and covaries with familial schizophrenia-spectrum disorder. A review of the research also shows that the non-clinical phenotype is associated extensively with schizophrenia-related risk factors, including social, environmental, substance use, obstetric, developmental, anatomical, motor, cognitive, linguistic, intellectual and psychopathological risk factors. The criterion and construct validity of the non-clinical psychosis phenotype with schizophrenia demonstrates that it is a valid population in which to study the aetiology of psychosis. Furthermore, it suggests shared genetic variation between the clinical and non-clinical phenotypes. Much remains to be learned about psychosis by broadening the scope of research to include the non-clinical psychosis phenotype.
\end{abstract}

Received 23 March 2010; Accepted 9 April 2010; First published online 19 May 2010

Key words: High risk, psychosis, psychotic symptoms, psychotic-like experiences.

\section{Introduction}

Psychotic symptoms, as highlighted by recent research, are experienced not just by patients with psychiatric disorders but also by a substantial proportion of the general healthy population. In the absence of illness, these symptoms are also referred to as psychotic-like experiences (PLEs) or subclinical psychotic symptoms. A recent meta-analysis by van Os et al. (2009) reported a median prevalence of $5-8 \%$ for these symptoms in the general population. Data on adolescents suggest that rates of PLEs are even higher among this age group (Poulton et al. 2000; Spauwen et al. 2003; Yoshizumi et al. 2004; Laurens et al. 2007). Clinical cases of psychosis, then, represent only a small proportion of the total phenotypic continuum of psychosis, with the major proportion made up of a much commoner non-clinical psychosis phenotype (individuals who experience PLEs).

\section{PLEs share criterion validity with clinical psychosis}

A clinical continuum between PLEs and psychotic disorder was demonstrated in an influential paper

* Address for correspondence: Dr I. Kelleher, Department of Psychiatry, Royal College of Surgeons in Ireland, Education and Research Centre, Beaumont Hospital, Dublin 9, Ireland.

(Email : iankelleher@rcsi.ie)

(Email : marycannon@rcsi.ie) from the Dunedin birth cohort study (Poulton et al. 2000). Children aged 11 years who reported psychotic symptoms were shown to be at a 5- to 16-fold increased risk of schizophrenia-spectrum disorder in adulthood. This finding was replicated in an Australian sample by Welham et al. (2009), who showed that self-reported auditory hallucinations at age 14 years were associated with increased risk for psychotic disorder at age 21. Similarly, in the general adult population, Hanssen et al. (2005) found that $8 \%$ of those who experienced PLEs were clinically psychotic 2 years later. Individuals who report PLEs (the non-clinical psychosis phenotype) can therefore be considered to represent a high-risk group for psychotic illness. As with research involving the offspring of parents with psychotic disorders (the 'genetic' high-risk approach), research with persons who report PLEs also provides a unique high-risk paradigm for studying the developmental trajectory to psychosis (the 'symptomatic' high-risk approach).

\section{PLEs share construct validity with clinical psychosis}

In the elegant paper by Mackie et al. (2010), in addition to identifying two discrete developmental trajectories for PLEs ('persistent' and 'increasing'), the authors identify several risk factors associated with these symptoms that have previously been recognized as 
risk factors for schizophrenia; namely, victimization (with associated elevated depressive and anxiety scores) and substance use. These findings add to the growing body of information on PLEs and the overlap with risk factors for schizophrenia. A wide range of risk factors for schizophrenia has now been investigated in individuals who report PLEs and some striking similarities have emerged between the nonclinical and clinical populations, demonstrating construct validity between the clinical and non-clinical phenotypes.

\section{Familiality and heritability}

Hanssen et al. (2006) investigated PLEs among 257 members of the general population and reported familial clustering of the symptoms, in line with findings in family and adoption studies in schizophrenia. Furthermore, Polanczyk et al. (2010) have shown familial covariation of PLEs with maternal schizophreniaspectrum disorder, and also with family psychiatric hospitalizations and family suicide attempts. Twin studies have also established that PLEs are heritable, with studies showing greater concordance for PLEs among monozygotic than dizygotic twins (Lataster et al. 2009; Polanczyk et al. 2010). Research on contributing genes or loci, however, is lacking.

\section{Schizophrenia-related social risk factors}

An elevated incidence of schizophrenia has been consistently demonstrated among migrant and ethnic minority groups, particularly African-Caribbeans in the UK (Fearon et al. 2006). Johns et al. (2002) found a similar pattern among individuals who report PLEs, with persons of African-Caribbean descent 2.5 times more likely to admit to hallucinations than the white British population. Similarly, Laurens et al. (2008) found that PLEs were more commonly reported by British children of African-Caribbean ethnicity than by white British children. Although they did not find a significant association with migration status, a larger representative Australian study of more than 10000 people showed that migrants from non-Englishspeaking backgrounds were more likely to report PLEs on interview (Scott et al. 2006). Further social risk factors for schizophrenia, including unemployment, lower socio-economic background and being unwed or divorced, were also replicated in this large Australian sample. Similarly, a higher rate of urbanicity, one of the most frequently reported findings in schizophrenia (Krabbendam \& van Os, 2005), was also demonstrated in association with PLEs.
Schizophrenia-related adverse childhood experiences risk factors

The prevalence of PLEs has been shown to be greater in adolescents who have had traumatic experiences, including physical abuse (Kelleher et al. 2008), unwanted sexual experiences (Lataster et al. 2006) and exposure to domestic violence (Kelleher et al. 2008). An association has also been reported between peer victimization and risk of PLEs, with higher rates of PLEs reported by victims of bullying (Campbell \& Morrison, 2007; Schreier et al. 2009; Mackie et al. 2010), but also, conversely, by perpetrators of bullying (Kelleher et al. 2008; Nishida et al. 2008) and, most strikingly, by children who are both victims and perpetrators of bullying ('bully/victims') (Kelleher et al. 2008). Mothers of children with PLEs have also been demonstrated to show increased levels of negative expressed emotion, although no difference was found in terms of maternal warmth (Polanczyk et al. 2010).

\section{Schizophrenia-related substance use risk factors}

The well-established relationship between psychotic disorder and cannabis use has been replicated in adolescents with PLEs (Miettunen et al. 2008; Harley et al. 2009). In their paper, Mackie et al. (2010) show that among adolescents who follow a trajectory of increasing PLEs over 2 years, a rise in cannabis use preceded a sharp increase in symptoms. Henquet et al. (2005), similarly, showed that the risk for PLEs among adolescents and young adults increased in a doseresponse manner relative to the frequency of cannabis use over a 4-year period. Harley et al. (2009) demonstrated an interesting synergistic interaction between cannabis use and traumatic childhood events, with exposure to both variables associated with a greater risk of PLEs than the summed risk that each variable accounted for individually. Both alcohol dependence and tobacco use have also been shown to be more common among individuals who report PLEs (Johns et al. 2004; Wiles et al. 2006).

\section{Schizophrenia-related obstetric and developmental deficits}

Adverse prenatal and perinatal events, including maternal infection and obstetric complications, are well documented in schizophrenia (Clarke et al. 2006, 2009). These findings have been replicated in persons who report PLEs (Zammit et al. 2009). Neuromotor deficits have also been demonstrated among adolescents who report PLEs (Cannon et al. 2002; Blanchard et al., in press). However, associations with advanced paternal age and with winter and spring 
births have failed to be shown (Zammit et al. 2008; Polanczyk et al. 2010).

\section{Schizophrenia-related neuroanatomical abnormalities}

Neuroimaging research has demonstrated significant overlaps between the clinical and non-clinical psychosis phenotypes. The typical functional magnetic resonance imaging (fMRI) profile of hypofrontality in schizophrenia has been replicated in adolescents who report PLEs, particularly in relation to the right cerebral hemisphere, and the classic frontotemporal disconnection now well established in clinical psychosis (Friston \& Frith, 1995) has also been demonstrated (Jacobson et al. 2010). Deficits in white matter integrity have been identified, in addition to grey matter abnormalities, although, of interest, adolescents who reported PLEs demonstrated larger grey matter volumes in contrast to the grey matter deficits typically seen in schizophrenia (Jacobson et al. 2010).

\section{Schizophrenia-related deficits in IQ, cognition and language}

Lower IQ scores have been demonstrated in the nonclinical psychosis population, as in schizophrenia (Cannon et al. 2002; Johns et al. 2004; Horwood et al. 2008). To date, however, there have been few studies of cognition for the non-clinical phenotype. Deficits in receptive, though not expressive, language have been reported among adolescents with PLEs (Cannon et al. 2002; Blanchard et al., in press). Blanchard et al. (in press) also demonstrated deficits in speed of processing in the non-clinical phenotype. Men who report PLEs have been shown to perform worse in tests of verbal fluency (Krabbendam et al. 2005).

\section{Schizophrenia-related co-morbid psychopathology}

Nishida et al. (2008) assessed a general population sample of more than 5000 adolescents for both the presence of PLEs and a range of psychopathologies. Adolescents who reported PLEs showed increased levels of anxiety, suicidal ideation and self-harm behaviours. Scott et al. (2009) found that adolescents who reported PLEs scored higher in symptoms of depression and were 2.7 times more likely to receive a diagnosis of depressive disorder. PLEs were also associated with child psychopathology on parent-rated measures. Polanczyk et al. (2010) replicated the findings for depressive and anxiety symptoms and selfharm and suicidal behaviour, and also demonstrated an increase in antisocial behaviour among adolescents who reported PLEs.

\section{Discussion and implications}

The past decade of research summarized above illustrates a non-ambiguous continuum between the clinical and non-clinical psychosis phenotypes in the general population. PLEs are familial, heritable, confer increased risk for schizophrenia-spectrum disorder and covary with maternal psychotic disorder. Furthermore, these symptoms share an extensive range of social, environmental, substance use, obstetric, developmental, anatomical, motor, cognitive, linguistic, intellectual and psychopathological risk factors with schizophrenia (see Table 1).

Although the rapid nervous system changes that take place in adolescence are recognized to be of great significance in the development of clinical psychosis, the low disease incidence hinders attempts to study the developmental trajectory in large numbers prior to the onset of illness (given that only about one in every hundred children studied will develop schizophrenia). The findings presented here, however, demonstrate that the non-clinical psychosis phenotype represents a valuable, and valid, population in which to study the aetiology of psychosis, with the further advantages that this non-clinical phenotype (i) is more prevalent than the clinical (disease) phenotype, thus increasing the population pool for study, (ii) can be screened for using a validated brief questionnaire (Kelleher et al. 2009) and (iii) facilitates research into early (pre-morbid, pre-medication) neurodevelopmental changes in psychosis.

Much has been learned about this population, but more remains to be discovered, especially in terms of neuro-genetics, -cognition and -anatomy. Genetic research may be particularly valuable in elucidating the molecular mechanisms underlying psychosis because the construct and criterion validity between the clinical and non-clinical psychosis phenotypes suggests that genetic risk may be shared between both. That is, genetic risk for psychosis may relate to the broader (clinical and non-clinical) psychosis phenotype rather than specifically to psychotic disorder. Genetic research to date has used the simple dichotomy of persons with psychotic disorder compared to the general population. However, the reasonably common non-clinical psychosis phenotype in the general population may have masked genes of importance.

The identification of a non-clinical psychosis phenotype raises interesting evolutionary questions (Kelleher et al., in press). Psychotic disorders are highly heritable and exert strong negative fitness effects but persist despite selective disadvantage. The identification of a non-clinical psychosis phenotype, however, opens up the possibility that there may 
Table 1. Aetiological and risk factor continuity between clinical and non-clinical psychosis phenotypes

\begin{tabular}{|c|c|c|c|}
\hline Category & Risk factor & $\begin{array}{l}\text { Schizophrenia } \\
\text { (clinical } \\
\text { psychosis } \\
\text { phenotype) }\end{array}$ & $\begin{array}{l}\text { PLEs (non- } \\
\text { clinical } \\
\text { psychosis } \\
\text { phenotype) }\end{array}$ \\
\hline \multirow[t]{2}{*}{ Genetics/transmission } & Familial & + & + \\
\hline & Heritable & + & + \\
\hline \multirow[t]{6}{*}{ Social } & Urbanicity & + & + \\
\hline & Migration & + & + \\
\hline & Ethnic minority & + & + \\
\hline & Low socio-economic background & + & + \\
\hline & Unemployed & + & + \\
\hline & Unmarried/divorced & + & + \\
\hline \multirow[t]{5}{*}{ Adverse childhood experiences } & Traumatic childhood physical or sexual experiences & + & + \\
\hline & Bullying/victimization & + & + \\
\hline & Parental domestic violence & + & + \\
\hline & Maternal expressed emotion: negativity & + & + \\
\hline & Maternal expressed emotion: warmth & + & - \\
\hline \multirow[t]{3}{*}{ Substance use } & Cannabis use & + & + \\
\hline & Tobacco use & + & + \\
\hline & Alcohol dependence & + & + \\
\hline \multirow[t]{5}{*}{ Obstetric and developmental deficits } & Obstetric complications & + & + \\
\hline & Maternal infection & + & + \\
\hline & Neuromotor deficits & + & + \\
\hline & Winter/spring birth & + & - \\
\hline & Paternal age & + & - \\
\hline \multirow[t]{4}{*}{ Neuroanatomy } & Hypofrontality & + & + \\
\hline & Frontotemporal disconnection & + & + \\
\hline & Grey matter abnormalities & + & + \\
\hline & White matter abnormalities & + & + \\
\hline \multirow[t]{4}{*}{ Cognition and language } & Verbal fluency & + & + \\
\hline & Receptive language & + & + \\
\hline & Expressive language & + & - \\
\hline & Speed of processing & + & + \\
\hline Intelligence & IQ & + & + \\
\hline \multirow[t]{5}{*}{ Psychopathology } & Depressive symptoms & + & + \\
\hline & Anxiety symptoms & + & + \\
\hline & Suicidal ideation & + & + \\
\hline & Self-harm & + & + \\
\hline & Antisocial behaviour & + & + \\
\hline
\end{tabular}

PLE, Psychotic-like experience.

+ , Positive findings; - , negative findings.

be selective advantages associated with genes that contribute to this phenotype but that also increase the risk for psychotic disorder. This biological compromise is not unique to psychosis; for example, genes that have been positively selected due to their protective effects against malarial infection bring with them the risk of sickle cell disease. Further investigation of this non-clinical population may help us to finally uncover an evolutionary basis for the persistence of psychosis genes in the general population.

\section{Conclusions}

Previous views of psychotic symptomatology as intrinsically pathological have been replaced by the idea that, in many cases, psychotic symptoms may fall within a spectrum of normal experience. Nonetheless, these symptoms are associated with increased risk for psychotic disorder and show criterion and construct validity for clinical psychosis. PLEs are familial, heritable, confer increased risk for schizophrenia-spectrum disorder, covary with maternal 
schizophrenia-spectrum disorder and share an extensive range of risk factors with schizophrenia. These findings indicate that the non-clinical psychosis phenotype represents a valid population for studying the aetiology of clinical psychosis and suggest a shared genetic aetiology between the clinical and nonclinical phenotypes. Much remains to be learned about psychosis by broadening the scope of research to include the non-clinical psychosis population.

\section{Acknowledgements}

M.C. is supported by a Health Research Board (Ireland) Clinician Scientists Award and a NARSAD Independent Investigator Award.

\section{Declaration of Interest}

None.

\section{References}

Blanchard MM, Jacobson S, Clarke M, Connor D, Kelleher I, Garavan H, Harley M, Cannon M (in press). Language, motor and speed of processing deficits in adolescents with subclinical psychotic symptoms. Schizophrenia Research.

Campbell ML, Morrison AP (2007). The relationship between bullying, psychotic-like experiences and appraisals in 14-16-year olds. Behaviour Research and Therapy 45, 1579-1591.

Cannon M, Caspi A, Moffitt TE, Harrington H, Taylor A, Murray RM, Poulton R (2002). Evidence for earlychildhood, pan-developmental impairment specific to schizophreniform disorder: results from a longitudinal birth cohort. Archives of General Psychiatry 59, 449-456.

Clarke MC, Harley M, Cannon M (2006). The role of obstetric events in schizophrenia. Schizophrenia Bulletin 32, 3-8.

Clarke MC, Tanskanen A, Huttunen M, Whittaker JC, Cannon M (2009). Evidence for an interaction between familial liability and prenatal exposure to infection in the causation of schizophrenia. American Journal of Psychiatry 166, 1025-1030.

Fearon P, Kirkbride JB, Morgan C, Dazzan P, Morgan K, Lloyd T, Hutchinson G, Tarrant J, Fung WL, Holloway J, Mallett R, Harrison G, Leff J, Jones PB, Murray RM (2006). Incidence of schizophrenia and other psychoses in ethnic minority groups: results from the MRC AESOP Study. Psychological Medicine 36, 1541-1550.

Friston KJ, Frith CD (1995). Schizophrenia: a disconnection syndrome? Clinical Neuroscience 3, 89-97.

Hanssen M, Krabbendam L, Vollema M, Delespaul P, van Os J (2006). Evidence for instrument and family-specific variation of subclinical psychosis dimensions in the general population. Journal of Abnormal Psychology 115, $5-14$.
Hanssen M, Maarten B, Rob B, Vollebergh W, van Os J (2005). The incidence and outcome of subclinical psychotic experiences in the general population. British Journal of Clinical Psychology 44, 181-191.

Harley M, Kelleher I, Clarke M, Lynch F, Arseneault L, Connor D, Fitzpatrick C, Cannon M (2009). Cannabis use and childhood trauma interact additively to increase the risk of psychotic symptoms in adolescence. Psychological Medicine. Published online: 9 December 2009. doi:10.1017/S0033291709991966.

Henquet C, Krabbendam L, Spauwen J, Kaplan C, Lieb R, Wittchen HU, van Os J (2005). Prospective cohort study of cannabis use, predisposition for psychosis, and psychotic symptoms in young people. British Medical Journal 330, 11.

Horwood J, Salvi G, Thomas K, Duffy L, Gunnell D, Hollis C, Lewis G, Menezes P, Thompson A, Wolke D, Zammit S, Harrison G (2008). IQ and non-clinical psychotic symptoms in 12-year-olds: results from the ALSPAC birth cohort. British Journal of Psychiatry 193, 185-191.

Jacobson S, Kelleher I, Harley M, Murtagh A, Clarke M, Blanchard M, Connolly C, O'Hanlon E, Garavan H, Cannon M (2010). Structural and functional brain correlates of subclinical psychotic symptoms in 11-13 year old schoolchildren. NeuroImage 49, 1875-1885.

Johns LC, Cannon M, Singleton N, Murray RM, Farrell M, Brugha T, Bebbington P, Jenkins R, Meltzer H (2004). Prevalence and correlates of self-reported psychotic symptoms in the British population. British Journal of Psychiatry 185, 298-305.

Johns LC, Nazroo JY, Bebbington P, Kuipers E (2002). Occurrence of hallucinatory experiences in a community sample and ethnic variations. British Journal of Psychiatry 180, 174-178.

Kelleher I, Harley M, Lynch F, Arseneault L, Fitzpatrick C, Cannon M (2008). Associations between childhood trauma, bullying and psychotic symptoms among a school-based adolescent sample. British Journal of Psychiatry 193, 378-382.

Kelleher I, Harley M, Murtagh A, Cannon M (2009). Are screening instruments valid for psychotic-like experiences? A validation study of screening questions for psychotic-like experiences using in-depth clinical interview. Schizophrenia Bulletin. Published online: 19 June 2009. doi:10.1093/schbul/sbp057.

Kelleher I, Jenner J, Cannon M (in press). Psychotic symptoms in the general population - an evolutionary perspective. British Journal of Psychiatry.

Krabbendam L, Myin-Germeys I, Hanssen M, van Os J (2005). Familial covariation of the subclinical psychosis phenotype and verbal fluency in the general population. Schizophrenia Research 74, 37-41.

Krabbendam L, van Os J (2005). Schizophrenia and urbanicity: a major environmental influence - conditional on genetic risk. Schizophrenia Bulletin 31, 795-799.

Lataster T, Myin-Germeys I, Derom C, Thiery E, van Os J (2009). Evidence that self-reported psychotic experiences represent the transitory developmental expression of genetic liability to psychosis in the general population. 
American Journal of Medical Genetics. Part B, Neuropsychiatric Genetics 150B, 1078-1084.

Lataster T, van Os J, Drukker M, Henquet C, Feron F, Gunther N, Myin-Germeys I (2006). Childhood victimisation and developmental expression of non-clinical delusional ideation and hallucinatory experiences: victimisation and non-clinical psychotic experiences. Social Psychiatry and Psychiatric Epidemiology 41, 423-428.

Laurens KR, Hodgins S, Maughan B, Murray RM, Rutter ML, Taylor EA (2007). Community screening for psychotic-like experiences and other putative antecedents of schizophrenia in children aged 9-12 years. Schizophrenia Research 90, 130-146.

Laurens KR, West SA, Murray RM, Hodgins S (2008). Psychotic-like experiences and other antecedents of schizophrenia in children aged 9-12 years: a comparison of ethnic and migrant groups in the United Kingdom. Psychological Medicine 38, 1103-1111.

Mackie CJ, Castellanos N, Conrod PJ (2010). Developmental trajectories of psychotic-like experiences across adolescence: impact of victimization and substance abuse. Psychological Medicine. Published online: 29 March 2010. doi:10.1017/S0033291710000449.

Miettunen J, Tormanen S, Murray GK, Jones PB, Maki P, Ebeling H, Moilanen I, Taanila A, Heinimaa M, Joukamaa M, Veijola J (2008). Association of cannabis use with prodromal symptoms of psychosis in adolescence. British Journal of Psychiatry 192, 470-471.

Nishida A, Tanii H, Nishimura Y, Kajiki N, Inoue K, Okada M, Sasaki T, Okazaki Y (2008). Associations between psychotic-like experiences and mental health status and other psychopathologies among Japanese early teens. Schizophrenia Research 99, 125-133.

Polanczyk G, Moffitt TE, Arseneault L, Cannon M, Ambler A, Keefe RSE, Houts R, Odgers CL, Caspi A (2010). Childhood psychotic symptoms share etiological and clinical features with adult schizophrenia: results from a representative birth cohort. Archives of General Psychiatry 67, 328-338.

Poulton R, Caspi A, Moffitt TE, Cannon M, Murray R, Harrington H (2000). Children's self-reported psychotic symptoms and adult schizophreniform disorder: a 15-year longitudinal study. Archives of General Psychiatry 57, 1053-1058.

Schreier A, Wolke D, Thomas K, Horwood J, Hollis C, Gunnell D, Lewis G, Thompson A, Zammit S, Duffy L,
Salvi G, Harrison G (2009). Prospective study of peer victimization in childhood and psychotic symptoms in a nonclinical population at age 12 years. Archives of General Psychiatry 66, 527-536.

Scott J, Chant D, Andrews G, McGrath J (2006).

Psychotic-like experiences in the general community: the correlates of CIDI psychosis screen items in an Australian sample. Psychological Medicine 36, 231-238.

Scott J, Martin G, Bor W, Sawyer M, Clark J, McGrath J (2009). The prevalence and correlates of hallucinations in Australian adolescents: results from a national survey. Schizophrenia Research 107, 179-185.

Spauwen J, Krabbendam L, Lieb R, Wittchen HU, van Os J (2003). Sex differences in psychosis: normal or pathological? Schizophrenia Research 62, 45-49.

van Os J, Linscott RJ, Myin-Germeys I, Delespaul P, Krabbendam L (2009). A systematic review and meta-analysis of the psychosis continuum: evidence for a psychosis proneness-persistence-impairment model of psychotic disorder. Psychological Medicine 39, 179-195.

Welham J, Scott J, Williams G, Najman J, Bor W, O'Callaghan M, McGrath J (2009). Emotional and behavioural antecedents of young adults who screen positive for non-affective psychosis: a 21-year birth cohort study. Psychological Medicine 39, 625-634.

Wiles NJ, Zammit S, Bebbington P, Singleton N, Meltzer $H_{\text {, }}$ Lewis G (2006). Self-reported psychotic symptoms in the general population: results from the longitudinal study of the British National Psychiatric Morbidity Survey. British Journal of Psychiatry 188, 519-526.

Yoshizumi T, Murase S, Honjo S, Kaneko H, Murakami T (2004). Hallucinatory experiences in a community sample of Japanese children. Journal of the American Academy of Child and Adolescent Psychiatry 43, 1030-1036.

Zammit S, Horwood J, Thompson A, Thomas K, Menezes P, Gunnell D, Hollis C, Wolke D, Lewis G, Harrison G (2008). Investigating if psychosis-like symptoms (PLIKS) are associated with family history of schizophrenia or paternal age in the ALSPAC birth cohort. Schizophrenia Research 104, 279-286.

Zammit S, Odd D, Horwood J, Thompson A, Thomas K, Menezes P, Gunnell D, Hollis C, Wolke D, Lewis G, Harrison G (2009). Investigating whether adverse prenatal and perinatal events are associated with non-clinical psychotic symptoms at age 12 years in the ALSPAC birth cohort. Psychological Medicine 39, 1457-1467. 